\title{
Relationships with God among Young Adults: Validating a Measurement Model with Four Dimensions
}

\author{
Nicolette D. Manglos-Weber* \\ Kansas State University \\ Margarita A. Mooney \\ Yale University \\ Kenneth A. Bollen \\ University of North Carolina-Chapel Hill \\ J. Micah Roos \\ Oklahoma State University
}

Experiencing a relationship with God is widely acknowledged as an important aspect of personal religiosity for both affiliated and unaffiliated young adults, but surprisingly few attempts have been made to develop measures appropriate to its latent, multidimensional quality. This paper presents a new model for measuring relationships with God based on religious role theory, attachment to God theory, and insights from interview-based studies, which allows for a wider array of dimensions than have been considered in prior work: anger, anxiety, intimacy, and consistency. To test our model's internal validity, we use confirmatory factor analysis with nationally representative data. To test its external validity, we (1) use difference-in-means tests across gender, race/ethnicity, geographical region, and religious affiliation; and (2) analyze correlations between our four new dimensions and four other commonly used measures of religiosity, thereby demonstrating both our model's validity and value for future studies of personal religiosity.

Key words: adolescents/youth; measurement; individual religiosity.

*Direct correspondence to Nicolette D. Manglos-Weber, Department of Sociology, Anthropology, and Social Work, Kansas State University, 200 Waters Hall, Manhattan, KS 66502, USA. E-mail:manglosweber@ksu.edu.

(C) The Author 2016. Published by Oxford University Press on behalf of the Association for the Sociology of Religion. All rights reserved. For permissions, please e-mail: journals. permissions@oup.com 
A central concern within the past 50 years of scholarship on American religion has been elucidating and measuring multiple dimensions of religiosity (Cornwall et al. 1986; Glock and Stark 1968; Lenski 1963). Yet much nationally representative survey research continues to focus heavily on affiliation and involvement patterns or tradition-specific beliefs and practices. More work is needed to measure dimensions of religiosity that may transcend differences in institutional commitment and identity. For research on young adults, this need is arguably even more pressing. Today's young adults are both less likely to be involved in organized religion than their elders and yet are often actively engaged in exploring multiple dimensions of personal religious belief and practice (Flory and Miller 2008; Pearce and Denton 2011; Wuthnow 2007).

Relationships with God comprise one such area in the study of personal religiosity that could benefit from improved measurement. Studies have found that narratives of interacting, conversing, and engaging with God pervade many Americans' daily lives, whether or not they attend a place of worship or even call themselves "religious" (Ammerman 2013b). Interviewees ranging from active Pentecostals and Catholic Charismatics to disaffiliated welfare mothers and homosexual believers focus on their personal bond with God-however conceptualized - as a central aspect of their everyday faith (Mooney 2014; Black 1999; Lee et al. 2012; Luhrmann 2012; Sullivan 2012; Wilcox 2002). The same goes for many in the millennial generation now transitioning into adulthood. An estimated 23 percent of this group report being neither religiously affiliated nor atheist or agnostic (Pew Research Center 2015), and many of them continue to demonstrate theistic orientations (Smith and Denton 2005:163-65).

What is also clear from the above research is that relationships with God are richer and more multifaceted than can be assessed by asking whether someone believes in God or what they imagine God to be like. Belief in God, as well as images of and beliefs about God, has been fairly well studied using survey data (Froese and Bader 2010; Hout and Fischer 2002; Hout and Greeley 1987). Yet research on images of God predominantly taps cognitive aspects rather than the experiential and behavioral aspects of many people's reported relationships with God. According to the framework of religious role theory, which emphasizes the centrality of the "God-role" and a corresponding set of reciprocal expectations between a person and God (Wikstrom 1987), the cognitive aspect of what people believe about God emerges from something deeper and more challenging to measure: how they experience the God-relation over time.

We develop a latent and multidimensional concept of relationships with God and evaluate its applicability for today's young adults, who may or may not be religiously affiliated or involved, but are influenced by American theistic culture (Ammerman 2013b). We use structural equation modeling with longitudinal panel data from the National Study of Youth and Religion (NSYR), a sample of young adults ages $24-29$, to evaluate the validity of this concept and to test inferences about four dimensions of relationships with God: intimacy, consistency, anxiety, and anger. To general scholarship on religion, we contribute a validated 
model for measuring important dimensions of personal religiosity—relationships with God-that can be analyzed with publically available data and further applied in other representative surveys. We therefore believe these analyses will be of interest to scholars of young adult religiosity as well as those concerned with the central questions of religious change and theism in America.

\section{LITERATURE REVIEW}

\section{Young Adults and Personal Religiosity}

Contemporary Americans are increasingly disaffiliated from historically influential religious institutions. This has been interpreted as a sign of the declining authority of those institutions and the privatization of religion (Chaves 1994, 2011:81ff). Yet many people still exhibit elements of personal religiosity. Some scholars have framed this in terms of expressive individualism and the crafting of a personal mosaic of religiosity (Bellah et al. 1985; Pearce and Denton 2011). Others caution against overstating the degree of eclecticism in Americans' beliefs and practices (McGuire 2008:185ff.). Still others find much that is shared among religious "individualists," most notably a theistic cultural package emphasizing belief in and relationship with God (Ammerman 2013b). Americans still overwhelmingly believe in God and most also believe that God is loving (Chaves 2011:10-11; Froese and Bader 2010:15), while a smaller majority also believe that God is engaged in human affairs (Froese and Bader 2010:26).

Today's young adults are in some ways even more likely to innovate on religious ideas and practices while being less interested in organized religion. Although certain aspects of young adulthood have also been associated with religious change among past generations, young adulthood today is even more uncertain and protracted and thus seems to promote religious disaffiliation even more than in the past (Arnett 2000; Bynner 2005; Johnson et al. 2011). Today's young adults face many obstacles to achieving the traditional markers of adulthood like financial independence, buying a home, getting married, and having children, which have historically supported involvement in organized religion (Silva 2012; Smith et al. 2011; Wuthnow 2007:20-49). They often navigate these tensions within and through their personal religiosity, developing frameworks that fit their developing identities and that are responsive to the effects of gender, class, race, and nationality (Flory and Miller 2008; Irby 2013; Wilkins 2008; Williams and Vashi 2007; Wuthnow 2007). Their shifting religiosity thus often rests uneasily with the fixed nature of organized religion (Wuthnow 2007:51-70), such that one in four millennials (i.e., those born between 1980 and 2000) now has no religious affiliation (Pew Research Center 2015).

At the same time, however, young adults often exhibit the kind of personal theism described above (Smith and Denton 2005:163-65). An estimated 72 percent of young adults ages 24-29 report belief in God, while another 16 percent say do not know or are unsure about this belief; and 50 percent view God as a personal being involved in the lives of people today. Among the unaffiliated, only 5 percent 
claim atheism, and only 4 percent believe in God but view God as an impersonal creator. The rest gravitate toward the categories of "don't know," "unsure," or "none of the above." In one sense, this suggests today's young adults follow in long-term trends of decline in religious involvement and persistence in personal religiosity. In another sense, it suggests current survey measures may yet be inadequate to capture their particular brand of theism or how they relate to God in their daily lives.

\section{Relationships with God}

Studies of everyday religion and personal religiosity have shown that in addition to beliefs about God, experiences of a reciprocal relationship with some conception of God are common among American adults. Scholars in this vein conceptualize personal religiosity as a sacred consciousness (Ammerman 2013a:292-94), which often emerges in moments of illness or crisis (McGuire and Kantor 1988), is particularly relied upon by those who are otherwise marginalized from society (Mooney 2014; Black 1999; Sullivan 2012), and is often rooted in a richly imaginative concept of God as a companion or friend (Ammerman 2013b). Echoing these findings in a qualitative study of adolescents, Pearce and Denton (2011) find that fully 50 percent of their sample-groups they call "Adapters" and "Assenters" - do not appear devout in terms of engagement in organized religion but do tend to report feeling very or somewhat close to God. ${ }^{2}$

The concept of the God-relation as a dimension of personal religiosity has received some theoretical attention, particularly by the mid-century psychologist Hjalmar Sundén (Wikstrom 1987). His religious role theory explains religious experiences as a function of perceiving a God-role in relation to oneself, with a set of expectations attached to each role in relation to the other. The relation is defined by reciprocity, not in the sequential, tit-for-tat sense, but in the sense of a set of complementary and cyclical expectations attached to each role (Manglos 2010:420; Black 1999). Confirmation of the relation is found in interpreting experiences and events - the beauty of the world, a fortuitous meeting — as God's actions that fulfill the God-role specific expectations (Wikstrom 1987:393), while allowing for an element of freedom on the part of the divine other to not always specifically act as desired, as demonstrated in research on prayer in both its answered and unanswered forms (Baesler 2002; Black 1999; Dein and Pargament 2012; Krause 2004). According to Sundén (Nelson 2009:130), the inner experience of relating to the divine other gives meaning to a wide variety of practices, from prayer, to religious service attendance, to living a moral lifestyle.

${ }^{1}$ These are weighted percentages from authors' analysis of the NSYR wave 4 data, which are similar to the findings of the Pew Forum Religious Landscapes Survey (Pew Forum 2015).

${ }^{2}$ This work and the following conceptualizations primarily apply to the majority of young adults who share cultural frameworks rooted in American Christianity, and much of the research on relationships with God focuses on evangelical Christianity. We find these studies to be the most applicable to our research since the majority of our sample- 86.14 percentidentifies as Christian, and since there is a lack of similar data from other groups. The applicability of these conceptualizations to non-Christian faiths requires further study. 
The findings of recent interview studies align with this theory. Lee et al. (2012:69) describe "partnering with the divine," by enacting benevolence in the context of a reciprocal relationship, as the very heart of religion. Luhrmann (2012) likewise describes active engagement in a reciprocal relationship with God as a central practice of Charismatic Christianity. She portrays this relationship as an object of intense imaginative work-picturing God at the other side of the table while drinking coffee, training oneself to hear and see God in mundane situations, and orienting oneself back to the relationship in spite of uncertainties, anxieties, or unanswered prayers.

These studies and others (Mooney 2009; Sullivan 2012) also highlight how relationships with God can be characterized by positive experiences like intimacy and consistency as well as negative experiences like anxiety or anger. One woman named Sheri describes how even as a young child, "I felt in my little heart at that age just this profound experience with God-his incredible closeness, his presence" (Lee et al. 2012:45), which her interviewers frame in terms of "divine intimacy" (Lee et al. 2012:45, italics added). Similarly, Sullivan (2012:38) shows that for young mothers in poverty, most of whom were minimally involved in religious groups, "God is close, intimate, a divine friend." In still other examples, however, relationships with God are described more in terms of consistency, or in other words steadiness and predictability. One young woman interviewed by Pearce and Denton (2011) explains: "I think I have become more religious just because there's been so many things, while out on your own ... you need someone who's always there and God's always there" (Pearce and Denton 2011:132). This quote locates her view of God's consistency as important in her life course transition from the security of her parent's home to the uncertainty of being "out on your own."

Yet relationships with God can also be tumultuous (Mooney 2009; Ellison and Henderson 2011:26; Luhrmann 2012; Sullivan 2012). Sullivan's (2012) interviews describe two parallel images of God as a loving father and God as a judge, who is at times "strict and disappointed" with them (p. 38). Luhrmann (2012:143) describes people for whom experiences of God induce feelings of anxiety because of their ambiguity, and because the person doubts their own ability to meet the demands of the relationship. Still other interviewees report experiences of anger, which seem to be associated with God's perceived failure to respond appropriately, and are surprisingly common among those who experience relationships with God (Lee et al. 2012). Some interviewees even talk about anger as, "a normal part of the process of experiencing divine love... as a signal that a deep relationship exists and is worth fighting for" (Lee et al. 2012:20).

In spite of this compelling theoretical framework, and the evidence to support its application among young adults in particular, the relationship with God itself has not often been measured using survey data in such a way that is appropriately sensitive to its latent and multidimensional quality. The work that has come closest is the attachment to God literature, which adapts Bowlby's $(1969,1988)$ works on parent-child attachment to conceptualize attachment to God along dimensions of avoidance and anxiety, where a secure attachment is one 


\section{SOCIOLOGY OF RELIGION}

absent of the prior two dimensions (Beck and MacDonald 2004; Granqvist 1998, 2003; Rowatt and Kirkpatrick 2002). Although there is good evidence for the validity of these constructs, we see two problems with this body of work. First, attachment to God dimensions has never been tested on a nationally representative sample, but has primarily been applied to convenience samples of religiously affiliated people. It is therefore unclear whether they have widespread applicability to the unaffiliated. Second, this theorization presumes that positive attachments are the direct converse of negative dimensions, yet the qualitative studies cited above point to the potential for positive and negative dimensions to co-exist. Our goal in this study, therefore, is to go beyond the attachment to God literature and develop valid measures for key dimensions of relationships with God, while also allowing for varying relations between them. In this way, we combine the insights of the qualitative literature on everyday religion, religious role theory, and attachment to God in order to improve representative survey analysis of generational trends in American religious life. We develop and test these measures on young adults because they seem to most thoroughly exemplify trends toward disaffiliation alongside a persistent theistic personal religiosity. Understanding their relationships with God is thus enlightening as to nature of these larger trends.

\section{DATA AND METHODS}

Since our goal is to validate multiple dimensions of relationships with God as latent constructs-going beyond the cognitive aspects of God-beliefs and capturing the experience of a reciprocal relationship over time-we rely on confirmatory factor analysis (CFA), a special case of structural equation modeling techniques (Bollen 1989:chap.7). Our starting point is to clarify the major concepts of interest and define their meanings. We represent each dimension of a concept as a latent variable in our model. We then create or find indicators that appear to tap the concept dimension as defined. Finally, we use CFA to test whether the relationships between the latent variables and their indicators are as we hypothesize. In other words, we subject our conceptual arguments to empirical tests (Bollen 1989:1-9; Pearl 2012). If our ideas are wrong, we expect to find poorly fitting models or indicators unrelated to their hypothesized latent variables. We base our empirical tests on waves 1 and 4 of the NSYR.

\section{Conceptualization and Pretests}

By design, CFA relies heavily on researchers' theories about key concepts, their definitions, and plausible measures of each, and these theories are rejectable based on empirical tests of the model (Bollen 1989; Borsboom et al. 2003). Proper conceptualizing at the outset is crucial. We developed our concept of relationships with God, and the four dimensions of intimacy, consistency, anxiety, and anger, through extended discussion among the authors, referring to the above-cited literature on religious role theory, personal religiosity in everyday 
life, and attachment to God. In using this literature, we relied on the original authors' own arguments and the concepts they drew from their data, since we found these authors' interests in relationships with God to closely parallel our own. We also drew on our prior research on personal religiosity (Mooney 2009; Manglos 2010; Mooney 2014). Given their regular reoccurrence across different qualitative studies and their alignment with religious role theory and attachment to God theory, we concluded that these four dimensions were most worthy of further conceptualization and measurement.

Through these discussions, we arrived at a definition of a relationship with God as an interactive bond between a person and God. The term "interactive" emerged from religious role theory, and suggests both that the bond is reciprocal and is experienced and enacted over time. The term "bond" is often used in the attachment literature, and suggests that such relationships can be understood as analogous to other binding ties such as family, friendship, or close partnership. We then developed definitions of each of the four dimensions as follows:

(1) Intimacy: The degree to which the bond is experienced as close and warm.

(2) Consistency: The degree to which the bond is experienced as steady and predictable.

(3) Anxiety: The degree to which the bond is characterized by worry and uncertainty.

(4) Anger: The degree to which failed expectations on the bond have resulted in feelings of hostility.

While engaged in this conceptualization process, we analyzed an existing survey data set intended to tap attachment to God according to dimensions of anxiety and avoidance (Beck and MacDonald 2004). ${ }^{3}$ We first ran CFA duplicating Beck and MacDonald's model structure, and then considered alternative model structures to the anxious and avoidant dimensions (see Supplementary Appendix for more details). Specifically, we attempted to fit a model structure with the latent four dimensions emerging from the above literature and our discussions to their data. Some of the Beck and MacDonald indicators, though not all of them, did seem to correlate with such latent constructs. In particular, their indicators worked fairly well for tapping the latent dimensions of anxiety and anger - which we would expect, given their conceptualization of attachments as anxious, avoidant, or secure. Yet the Beck and MacDonald data lacked appropriate measures of intimacy and consistency, aspects of the relationship with God which our literature review and discussion deemed significant.

Our next step, therefore, was to draft new items to measure intimacy and consistency, as well as a few new items to measure anxiety and anger, which we combined with the indicators from Beck and MacDonald data that worked well. The

${ }^{3}$ Data and codebook were generously provided by these authors. 
wording of these new items was developed through group discussion among the authors and in line with the proposed definitions above. This resulted in an index of 24 items (six per dimension) comprised our newly constructed indicators and the best-fitting indicators from the Beck and MacDonald data. We pretested these 24 items through an online survey among a convenience sample $(N=835)$ of undergraduates in a large Southeastern public university. We then conducted a second round of CFA using these pilot data. We determined that the 12 questions, listed in table 1 with their distributions, formed the best performing set of measurement indicators. The variable names marked with an asterisk are those adapted directly from Beck and MacDonald.

\section{Analyses of Nationally Representative Data}

After we successfully pretested the 12 items in table 1, these measures were included on the fourth wave of the NSYR, a panel study of young adults. This study has four waves of data, of which we use the first and the fourth waves. The first wave was a nationally representative telephone survey of 3,290 teenagers between the ages of 13 and 17, conducted between July 2002 and April 2003. The fourth wave was then conducted over the year of 2013, with a final sample size of 2,144, representing a 65 percent retention rate from wave 1 . There are 1,451 cases with data on our four dimensions of relationships with God. ${ }^{4}$ Wave 4 panel weights-which we use in all analyses - were missing for 49 cases, so the final weighted analysis sample is 1,402.

In the following Results section, we test the validity of our model structure against the NSYR data through a final round of CFA. We do this, again, to examine whether the variables we created appear to be influenced by the theorized latent variable. Our measurement hypotheses are that each indicator is influenced solely by its corresponding latent variable and its measurement error. Because our indicators are ordinal variables, we use the weighted least squares (WLSMV) estimator option in Mplus software (version 7.2), which treats the ordinal variables as collapsed versions of underlying continuous multivariate normal variables (Asparouhov 2005).

\footnotetext{
${ }^{4}$ The number of cases with full data was limited for two reasons. First, the skip pattern of the survey sought to identify any respondents who could be considered religious in some way. R's were first asked, "Do you think of yourself as part of a particular religion, denomination, or church?" If "yes," then they were asked about relationships with God. If "no," they were asked a follow-up question: "Regardless of where you may attend religious services or not, do you generally consider yourself to be Catholic, another kind of Christian, Jewish, Muslim, another religion, or not religious?" If they responded with any category other than "not religious," then they were asked the relationships with God questions. If they answered "not religious," then they were asked: "Do you consider yourself to be an atheist, agnostic, just not religious, or something else?" Those who selected atheist, agnostic, or not religious were then skipped on the relationship with God questions, while all others were not skipped. The second reason the cases are limited is due to a programming error in the online survey that caused 204 cases to be skipped on these questions when they should not have been. Bivariate tests revealed these cases were not significantly different from the larger sample on educational attainment, income, or religious attendance, so we assume little bias was introduced by the error.
} 
RELATIONSHIPS WITH GOD AMONG YOUNG ADULTS 201

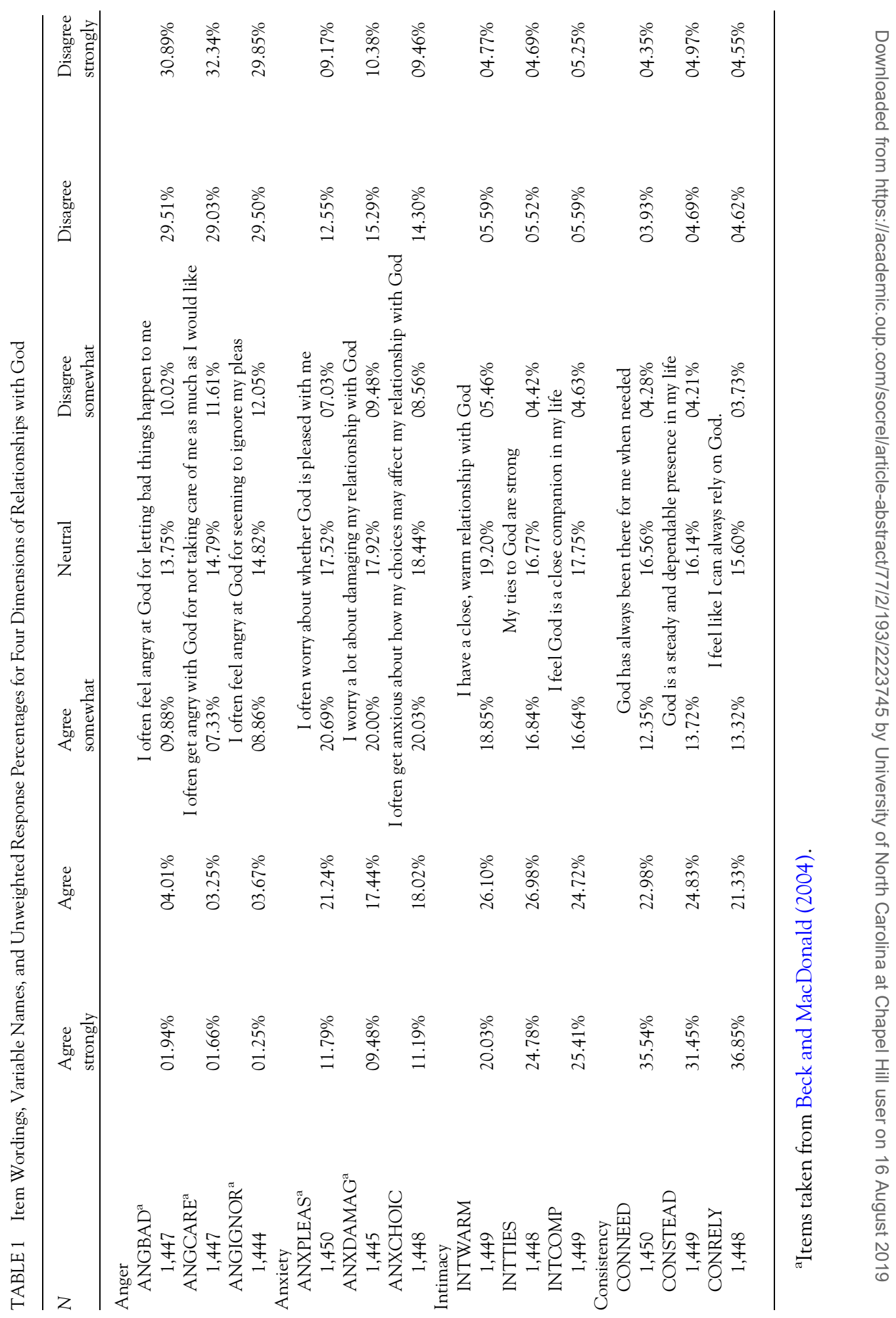


We use several tests of model fit. The first is a $\chi^{2}$ measure, where the null hypothesis is that the hypothesized model exactly explains the covariances and means of the indicator variables. This means that for the $\chi^{2}$ test, large $p$-values are favorable to the model while small $p$-values are evidence against it. We also use other overall fit statistics to supplement the $\chi^{2}$ : (1-RMSEA) (Bollen 1999; Browne and Cudeck 1993), the CFI (Bentler 1990), TLI (Tucker and Lewis 1973), and the BIC (Schwartz 1978). Conventional practice sets a lower limit for CFI, TLI, and (1-RMSEA) to 0.90 with values close to 1 as the best fit. The BIC is calculated as $T-\mathrm{df} \times \ln (N)$ where $T$ is the $\chi^{2}$ test statistic (Raftery 1995), df are the degrees of freedom, and $N$ is the sample size. Negative values of the BIC favor the hypothesized models, while positive ones are evidence against it. The more negative is the BIC, the better is the model fit.

After the CFA, we conduct two rounds of external validity tests. First, we analyze the association of each of our four dimensions to the following variables, which are often found to correlate with aspects of religiosity: gender (Sullins 2006), race/ethnicity (Ellison and Sherkat 1995), and region (Regnerus et al. 2004). We also look at how our dimensions correlate with religious affiliation by category. ${ }^{5}$ These analyses are meant to assess whether our measures are relevant across sociodemographic categories and for both affiliated and unaffiliated young adults, as theorized.

Second, we examine associations between our dimensions and four other commonly used measures of religiosity: frequency of religious service attendance, measured in six categories ranging from "more than once a week" to "a few times a year"; religious salience, measured on a five-category scale by the question, "How important or unimportant is religious faith in shaping how you live your life?"; frequency of prayer, measured by the question, "how often, if ever, do you pray alone?," and ranging across seven categories from "multiple times a day" to "never"; and closeness to God, measured by the question, "how distant or close do you feel to God most of the time?" These analyses test whether our dimensions correlate with these other measures - which we would expect if they are indeed valid dimensions of religiosity-and also verify that they are not so strongly

${ }^{5}$ Based on many years of study (Pearce and Denton 2011; Smith and Denton 2005; Smith and Snell 2009), NSYR personnel developed an adapted version of the common reltrad (Steensland et al. 2000) measure of American religious traditions. This new variable-tradrel-includes categories of Catholic, Mainline Protestant, Evangelical Protestant, Black Protestant, Jewish, Not Religious, and Other Religion, like the earlier measure, but also has a separate category for Mormon, and includes new categories that reflect trends away from denominational identities: Indeterminate Christian Attender and Indeterminate Christian Nonattender. Respondents were considered attenders who responded "yes" to the question, "Do you attend religious services more than once or twice a year, not counting weddings, baptisms, or funerals?" The variable also includes two other categories: "Indeterminate Attender" and "Indeterminate Nonattender," which we combine with the "Other Religion" and "Not Religious" categories, respectively. The original variable also splits Black Protestants into "Mainline" and "Conservative," but given the small number of cases in the "Mainline" group, we also combined these into one category. 
correlated that they would seem to be tapping underlying constructs that are hard to distinguish empirically.

\section{RESULTS}

\section{Distributions}

In table 1, we see that the measures of the four dimensions are very different in terms of their prevalence. Anger is least common, with percentages of those who agree strongly, agree, or somewhat agree with the three items hovering at around 15 percent. Slightly more report agreement with the items tapping anxiety, with a slim majority agreeing with these statements to any extent. Anxiety is also the most evenly distributed across the response categories. By contrast, it is quite common for respondents to agree with statements referring to God's intimacy and consistency.

\section{Confirmatory Factor Analyses}

In our initial CFA model, each of the four dimensions was measured with three indicators with uncorrelated errors of measurement.

This initial model (model 1) had a statistically significant $(p<.001) \chi^{2}$ value, which indicates some lack of fit. However, large sample sizes can often lead to high statistical power and significant $\chi^{2}$ tests. To supplement the $\chi^{2}$, we have several fit indices that we explained above. Our model satisfies the conventional standards of fit for each of these. We also looked at other model diagnostics to see if there was a way to improve the model. We found evidence that the ANXCHOIC item, "I often get anxious about how my choices may affect my relationship to God," loaded on multiple dimensions and otherwise served as a relatively poor indicator of anxiety. We dropped this item and re-estimated the model, as shown in the second row of table 2. Without having the same observed variables in the model, we cannot directly compare the fit of this second model with the first; yet it seems to have similar to a little better fit.

The diagnostics also suggest a possible association between INTWARM ("I have a close, warm relationship with God") and INTCOMP ("I feel God is a close companion in my life"). Notably, both prompts include the word "close," which could provoke a particular connotation for some and thus create an

TABLE 2 Model Fit for Original Model, Intermediary, and Final Models

\begin{tabular}{llllllr}
\hline Model & 1-RMSEA & CFI & TLI & \multicolumn{1}{c}{$\chi^{2}$} & df & \multicolumn{1}{l}{ BIC } \\
\hline 1: Original model & 0.943 & 0.998 & 0.997 & 263.44 & 47 & -77.11 \\
2: Removed "anxchoic" item & 0.949 & 0.999 & 0.998 & 170.61 & 37 & -97.48 \\
3: Added "close" factor & 0.964 & 0.999 & 0.999 & 99.66 & 36 & -161.19
\end{tabular}

Note: $N=1,402$ for all models. $\chi^{2}$ is significant at the $p<.001$ level for all models. 
association of these two variables beyond that created by their common dependence on intimacy. We address this by introducing a method factor associated with the use of the word "close" in the two items and permit this method factor to influence INTWARM and INTCOMP. Line 3 of table 2 suggests that the model with this method factor has the best profile of overall fit. Figure 1 shows the path diagram of the final model.

Table 3 gives information on the $R^{2}$ for the underlying indicators for each measure, which estimates how much variance in the indicator is explained by its respective latent variable(s). The best performing indicators on this metric are the indicators for intimacy and consistency, which have about 90 percent or more explained variance. Even the lowest values for the anxiety indicators are 0.7 or higher.

Table 4 estimates the correlations between the four different dimensions. The correlation of 0.95 between intimacy and consistency is unusually high for two theoretically distinct constructs, and we address this issue in the sensitivity tests below. The next largest correlation is between anxiety and consistency at over 0.5. The correlation of anxiety with intimacy is a bit lower at less than 0.4. Anger is negatively correlated with consistency and intimacy, but anxiety is positively correlated with the three others.

\section{Sensitivity Analyses}

We also performed several robustness checks on the final model. The first was the addition of positive and negative wording method factors. Because each of the items for both the intimacy and consistency dimension are generally positive and the items for both anger and anxiety are generally negative, it was possible that a portion of the shared covariance between these items was due to this

FIGURE 1. Path Diagram for Model 3 (Final Model).

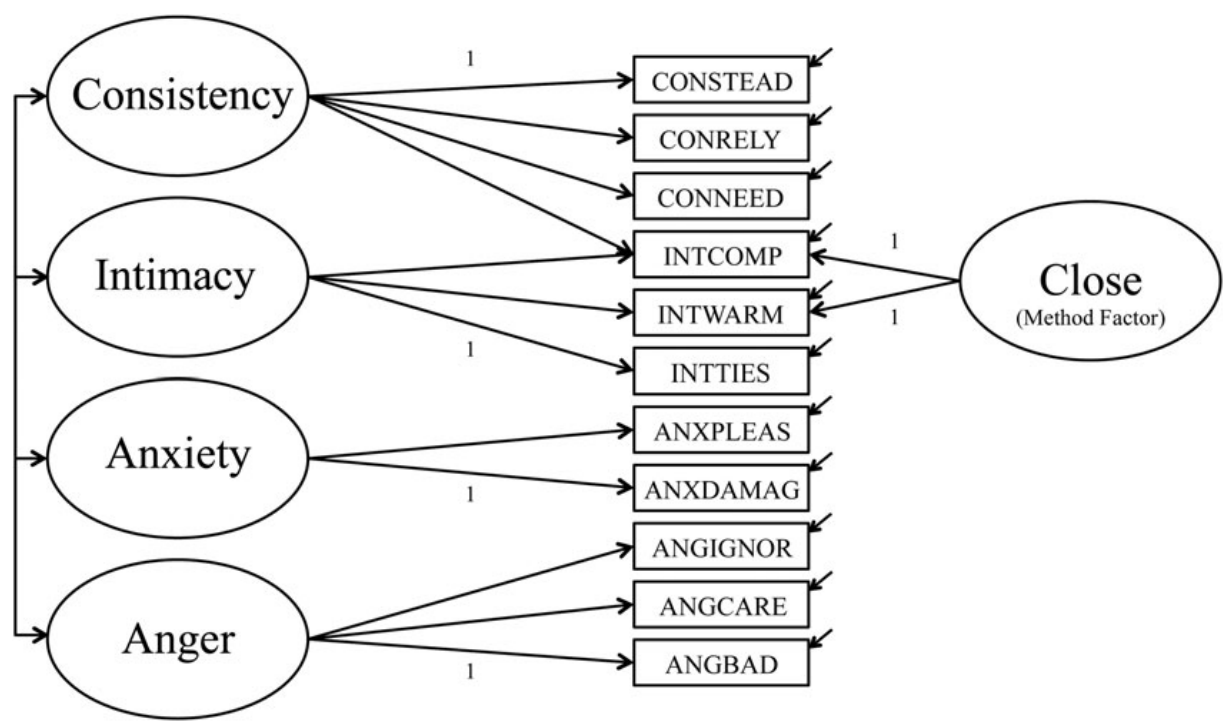


TABLE 3 Final Model $R^{2}$ Estimates of the Amount of Variance in the Underlying Indicator Explained by Its Corresponding Latent Variable

\begin{tabular}{lllr}
\hline Variable & Estimate & Residual S.E. & Est./S.E. \\
\hline Anger & & & \\
ANGBAD & 0.815 & 0.014 & 59.765 \\
ANGCARE & 0.810 & 0.015 & 55.798 \\
$\quad$ ANGIGNOR & 0.843 & 0.013 & 62.505 \\
Anxiety & & & \\
ANXPLEAS & 0.718 & 0.026 & 27.106 \\
ANXDAMAG & 0.756 & 0.026 & 28.563 \\
Intimacy & & & \\
INTTIES & 0.916 & 0.007 & 138.427 \\
INTCOMP & 0.934 & 0.005 & 174.397 \\
INTWARM & 0.961 & 0.007 & 137.622 \\
Consistency & & & 127.633 \\
CONSTEAD & 0.906 & 0.007 & 104.636 \\
CONRELY & 0.902 & 0.007 & \\
CONNEED & 0.868 & 0.008 & \\
\end{tabular}

Note: All values are significant at the $p<.001$ level.

methodological property. Each method factor was specified to be uncorrelated with the substantive dimensions (anger, anxiety, intimacy, consistency) and to be uncorrelated with each other (that is, the positive wording method factor did not correlate with the negative wording factor). This model produced similar estimates to model 3, without a commensurate improvement in fit. Additionally, because intimacy and consistency correlate so highly, a model where they were combined into a single factor was estimated. This three-factor model had poorer fit than model $3\left(\chi^{2}=389.224, \mathrm{df}=40, p\right.$-value $=<.0001 ; \mathrm{CFI}=0.996$; $\mathrm{TLI}=0.995 ; \mathrm{BIC}=99.40)$ by some of the fit indices. This is evidence that while highly correlated, the intimacy and consistency factors are distinct.

TABLE 4 Correlations between Dimensions of Relationships with God

\begin{tabular}{lcc}
\hline Factors & Correlation & S.E. \\
\hline Anger with anxiety & 0.309 & 0.029 \\
Anger with intimacy & -0.244 & 0.024 \\
Anger with consistency & -0.302 & 0.022 \\
Anxiety with intimacy & 0.398 & 0.024 \\
Anxiety with consistency & 0.523 & 0.022 \\
Intimacy with consistency & 0.954 & 0.004
\end{tabular}

Note: All correlations are significant at the $p>.001$ level. 


\section{SOCIOLOGY OF RELIGION}

\section{External Validity Tests}

To test external validity, we first examine the association between each dimension and the previously identified demographic variables. We regress the four RWG dimensions on dichotomous variables for these demographic characteristics (using survey weights) one at a time (i.e., the mean difference for one demographic category, such as gender, is without controlling for region, religious affiliation, or race/ethnicity).

At the top of table 5, we see there are only significant differences between men and women in mean values for intimacy and consistency. On the other hand, blacks have significantly higher mean values than whites on anxiety, intimacy, and consistency, while Hispanics have significantly higher mean values of anxiety and consistency than whites but are closer to whites in their values for intimacy. By region, we see higher levels of intimacy, consistency, and anxiety in

TABLE 5 Differences in Mean Values of Four Dimensions of Relationships with God across Groups and Other Commonly Used Measures of Religiosity

\begin{tabular}{|c|c|c|c|c|}
\hline & ANG. & ANX. & INT. & CON. \\
\hline \multicolumn{5}{|l|}{ Gender } \\
\hline Female & -0.041 & -0.017 & $0.208 * *$ & $0.224 * *$ \\
\hline \multicolumn{5}{|l|}{ Race/ethnicity } \\
\hline Black & -0.069 & $0.578 * * *$ & $0.461 * * *$ & $0.702 * * *$ \\
\hline Hispanic & 0.045 & $0.400 * * *$ & $0.182+$ & $0.471 * * *$ \\
\hline Other & 0.156 & 0.224 & 0.166 & 0.120 \\
\hline \multicolumn{5}{|l|}{ Region } \\
\hline Northeast & 0.011 & 0.075 & 0.031 & -0.009 \\
\hline South & -0.083 & $0.260 * *$ & $0.213 * *$ & $0.270 * *$ \\
\hline West & $-0.167+$ & 0.027 & 0.150 & 0.116 \\
\hline \multicolumn{5}{|l|}{ Affiliation } \\
\hline Evangelical Protestant & -0.060 & $0.754 * * *$ & $1.157 * * *$ & $1.355 * * *$ \\
\hline Mainline Protestant & 0.185 & $0.482 * * *$ & $0.617 * * *$ & $0.726 * * *$ \\
\hline Black Protestant & -0.000 & $0.473 * *$ & $0.949 * * *$ & $1.082 * * *$ \\
\hline Catholic & 0.146 & $0.499 * * *$ & $0.457 * * *$ & $0.452 * * *$ \\
\hline Jewish & 0.002 & 0.043 & -0.075 & -0.029 \\
\hline Mormon & $-0.377+$ & $0.854 * * *$ & $1.396 * * *$ & $1.454 * * *$ \\
\hline Other religion & $-0.410 *$ & $0.445 * *$ & 0.071 & $0.259+$ \\
\hline Indeterm. Christian attender & -0.002 & $0.515 * * *$ & $1.107 * * *$ & $1.064 * * *$ \\
\hline Indeterm. Christian nonattender & $0.224+$ & $0.572 * * *$ & $0.477 * * *$ & $0.522 * * *$ \\
\hline Frequency of prayer & $-0.133 * * *$ & $0.338 * * *$ & $0.664 * * *$ & $0.668 * * *$ \\
\hline Service attendance & $-0.149 * * *$ & $0.153 * * *$ & $0.429 * * *$ & $0.460 * * *$ \\
\hline Salience & $-0.152 * * *$ & $0.407 * * *$ & $0.710 * * *$ & $0.737 * * *$ \\
\hline Closeness to God & $-0.316 * * *$ & $0.150 * * *$ & $0.815 * * *$ & $0.747 * * *$ \\
\hline
\end{tabular}

Note: Reference categories are as follows: (1) white/non-Hispanic; (2) midwest; and (3) no religious affiliation. 
the south, which is expected, given the higher levels of religiosity along multiple dimensions in that region.

Concerning differences by affiliation, two overall patterns strike us as important. First, aligning with what we know about the emphasis on personal relationships with God in these traditions, Evangelical Protestants, Black Protestants, and Mormons exhibit the highest levels of intimacy and consistency. On the other hand, Evangelical Protestant and Mormon groups also exhibit significantly higher levels of anxiety. Second, of all of our dimensions, anger demonstrates the least variation across religious affiliation categories. We know from table 1 that high values of anger are less frequent in the sample generally than high levels of other dimensions, and here we see that anger is also unlike the other dimensions in how strongly it correlates with certain religious affiliations.

For the second round of external validity checks, we report correlations (rather than mean differences) between our four dimensions and four other commonly used measures of religiosity in the bottom rows of table 5. Notably, these measures vary by type. Some are behaviors (prayer and attendance), while others are perceptions (salience) or emotions (felt closeness to God). They all exhibit strong correlations with each of our dimensions; however, the strength and direction of the correlations vary across the four dimensions of relationships with God. Overall, intimacy, consistency, and anxiety are positively correlated, while anger is negatively correlated with the other religiosity measures. We see the strongest correlations with our intimacy and consistency measures for religious salience and felt closeness to God. Yet salience is much more strongly correlated with anxiety than is felt closeness to God. Attendance, on the other hand, illustrates some of the weakest associations with our measures, although all the correlations remain significant and goes in the same direction. None of the correlations are strong enough to suggest, however, that our new dimensions are redundant with the others; and ancillary tests of felt closeness to God as a potential additional indicator of intimacy illustrated poor model fit, providing further evidence that they are tapping related but different constructs.

\section{DISCUSSION}

Our goal at the outset of this study was to investigate whether we could measure four different dimensions to relationships with God (anger, anxiety, intimacy, and consistency) comprising unique dimensions of personal religiosity among young adults, as suggested by existing literature and our own past research (Mooney 2009; Mooney 2014; Lee et al. 2012; Luhrmann 2011; Pearce and Denton 2011; Smith and Denton 2005; Sullivan 2012). We developed and pretested a measurement model and evaluated its validity for a nationally representative sample of young adults. The model comprises 12 indicators-three for each dimension - that combine existing items from an Attachment to God scale (Beck and MacDonald 2004) and those we constructed collaboratively based on their face validity. We found strong empirical support for the internal and 
external validity of these four dimensions, and conclude that they comprise valuable new measures of personal religiosity that are grounded in work on everyday religion (Ammerman 2013a, 2013b; Luhrmann 2011; Sullivan 2012) and complement other studies of personal religiosity among both affiliated and unaffiliated young adults (Flory and Miller 2008; Pearce and Denton 2011; Wuthnow 2007).

Our results further suggest these dimensions should be treated as distinct, since they each demonstrate different patterns across the young adult population, different relationships to each other, and different relationships to other measures of religiosity. Two central findings support this conclusion. First, the two positive dimensions of intimacy and consistency go together-as evidenced by their high degree of correlation - in a way that the two negative dimensions of anxiety and anger do not. This makes conceptual sense, we would argue. The sense that God is consistently present would be supportive of feelings of closeness, as the attachment literature would say about parent-child relationships. Likewise, affection generates a sense of reliability and trustworthiness, so felt intimacy is going to enhance one's view of God's consistency. We would therefore suggest—although further work on this is needed - that intimacy and consistency can be thought of two aspects of a close, positive God-relationship. Yet we also maintain that intimacy and consistency should be considered as separate constructs, particularly because the emotional content of a person's relationships with God expressed as intimacy is going to vary (note that there are more feelings-oriented words on the intimacy questions than the consistency questions); and because a sense of God's consistency is potentially going to be more related to actual events and how they are interpreted (i.e., answered versus unanswered prayers, degree of stress and trauma).

Second, we find that anxiety and anger do not go together in the same way, but are in fact negatively correlated, suggesting they can be thought of as two fairly different expressions of challenging experiences within the God-relation. The anxiety dimension is more closely related to both the positive dimensions of relationships with God and other measures of religiosity, suggesting that it is a negative experience more common to those who are nonetheless religiously active, devout, or engaged. Indeed, worry is indicative of concern-one does not worry about relationships that have no meaning or value-and thus it is reasonable that those with more intimate and consistent relationships with God would also experience more anxiety. Additionally, people affiliated with certain denominations (such as Evangelical Protestants and Mormons) exhibit the greatest differences from the nonreligious in anxiety. Thus, anxiety could be linked to the effects of certain organized religious environments that place heavy demands on members and have a strict emphasis on moral conduct. It is also possible that young people who are already prone to anxiety about their God-relationship may self-select into a religious milieu that both validates that anxiety and provides strict models of behavior.

In contrast, anger appears to be more common among those who are less religious on multiple measures, suggesting it is indicative of distance and/or 
alienation. Further, the items measuring anger exhibit much lower values than consistency but also seem to vary less between racial/ethnic, gender, regional, and denominational groups. We would suggest this is partly because the items tapping anger imply a degree of disappointment about events in one's life, which could be induced by unusually high levels of stress or trauma. We would also suggest that having anger toward God assumes a strong view of God as somehow responsible for events in one's life. Thus, a person would have to both (1) believe God is personally involved (or should/can be) in the events of their life and (2) have experienced strong disappointments or stress in life to experience anger with God. This is why it exhibits the lowest values of the four dimensions, but it could also explain the absence of strong differences across groups. Put differently, anger would depend less on things like race, denomination, gender, etc. and more on things like externalizing traits and the nature and extent of stressful events in one's life.

Of course, any attempt to produce more refined and valid measures inevitably comes up against questions of replicability and applicability to other demographic groups. Given past findings on the pervasiveness of theistic religiosity among a broader age range of adults (Ammerman 2013b), we expect they might have value beyond young adults, but future research would be needed to address that question. It is also unclear whether these dimensions could be adapted to study personal religiosity within other faiths, especially nontheistic faiths like Hinduism or Buddhism, which are not well represented in our sample. Our findings most closely capture the experiences of young adults who follow or are most influenced by American Christianity. Despite these limitations, because these measures are both thoroughly validated and included in a large scale, nationally representative longitudinal survey data set available for public use, they comprise a significant innovation in knowledge about personal religiosity among young adults and suggest important further avenues for research.

For example, we expect these dimensions to be particularly useful for answering new research questions about religion and health and about the relationship between social ties and religiosity. Would the generally positive association between religion and health look the same if we looked at the anger dimension of the relationship to God? Would this association be even stronger if we included measures of intimacy and consistency? Additionally, if young people have certain positive or negative experiences in relations with God, are these accompanied by similar experiences in their relations with friends and family? Our new measures, we argue, are better suited to address these questions than existing measures of personal religiosity such as God-beliefs or religious salience.

Finally, the bivariate results we provide are suggestive of distinct patterns of relationships with God for young adults across gender and racial/ethnic categories. Given what we know about how women within Christianity and Judaism tend to be more religious than men (Sullins 2006), and how blacks are more involved in religious groups than whites (Ellison and Sherkat 1995), it would be helpful to determine how much of these broader differences are rooted in 
differences in how these groups relate to God, or conversely whether differences in relationships with God arise as a result of different religious involvement patterns. A similar question could be raised in regard to the relationships between our dimensions and other measures of religiosity. It is unclear from these analyses, for example, whether relationship with God dimensions influence prayer and religious service attendance or vice versa. Nevertheless, the fact that they are strong and consistent, and yet look different for each of the relationship with God dimensions, suggest that we are indeed tapping into four distinct constructs that are aspects of relationships with God specifically and religiosity more generally.

\section{CONCLUSION}

In this study, our aim was to improve on existing measures of personal religiosity, in order to better evaluate the dynamics of theistic experiences among the many young adults who may or may not be affiliated with organized religion as highlighted in prior literature (Flory and Miller 2008; Pearce and Denton 2011; Wuthnow 2007). To that end, we focused on relationships with God as a latent and multidimensional construct, combining the conceptual contributions of work on everyday religion, religious role theory, and attachment to God (Ammerman 2013a; Mooney 2009; Beck and MacDonald 2004; Lee et al. 2012; Luhrmann 2012; Sullivan 2012; Wikstrom 1987). The result is an empirically validated measurement model with four dimensions of relationships with God-intimacy, consistency, anxiety, and anger-comprising valuable new measures of personal religiosity.

We hope that these measures will provide new ways of looking at young adult religiosity as it pertains to God in a way that is not necessarily dependent on religious affiliation or involvement. Many young adults who are not religious by affiliation, practice, or commitment still indicate they have a bond with God that includes both positive and negative aspects. They frame events and experiences in terms of the God-relation and the expectations on both sides. Thus, these new conceptually grounded instruments to measure relationships with God help to illuminate a dimension of religion that is important for many young adults regardless of their affiliation.

\section{SUPPLEMENTARY MATERIAL}

A supplementary section is located with the electronic version of this article at Sociology of Religion online (http://www.socrel.oxfordjournals.org).

\section{ACKNOWLEDGMENTS}

We thank Jade Avelis for her invaluable research assistance, Sara Skiles for administrative support, and Christian Smith for consulting on research design. 


\section{FUNDING}

Work for this article was supported by the John Templeton Foundation, Grant \#34495.

\section{REFERENCES}

Ammerman, Nancy Tatom. 2013a. Sacred Stories, Spiritual Tribes: Finding Religion in Everyday Life. New York: Oxford University Press.

- 2013b. "Spiritual but Not Religious? Beyond Binary Choices in the Study of Religion." Journal for the Scientific Study of Religion 52, no. 2:258-78.

Arnett, Jeffrey Jensen. 2000. "Emerging Adulthood." American Psychologist 55, no. 5:469-80.

Asparouhov, Tihomir. 2005. "Sampling Weights in Latent Variable Modeling." Structural Equation Modeling: A Multidisciplinary Journal 12, no. 3:411-34.

Baesler, E. James. 2002. "Prayer and Relationship with God II: Replication and Extension of the Relational Prayer Model." Review of Religious Research 44, no. 1:58-67.

Beck, Richard, and Angie MacDonald. 2004. "Attachment to God: The Attachment to God Inventory, Tests of Working Model Correspondence, and an Exploration of Faith Group Differences." Journal of Psychology and Theory 32, no. 2:92-103.

Bellah, Robert N., Richard Madsen, William M. Sullivan, Ann Swidler, and Steven M. Tipton. 1985. Habits of the Heart: Individualism and Commitment in American Life. Berkeley, CA: University of California Press.

Bentler, P. M. 1990. "Comparative Fit Indexes in Structural Models." Psychological Bulletin 107, no. 2:238-46.

Black, Helen K. 1999. "Poverty and Prayer: Spiritual Narratives of Elderly African-American Women." Review of Religious Research 40, no. 4:359-74.

Bollen, Kenneth A. 1989. Structural Equations with Latent Variables. New York: Wiley.

_. 1999. "Subject: RMSEA Simple Suggestion." SEMNET listserv archive. January 28, 1999.

Borsboom, Denny, Gideon J. Mellenbergh, and Jaap Van Heerden. 2003. "The Theoretical Status of Latent Variables." Psychological Review 110, no. 2:203-19.

Bowlby, John. 1969. Attachment. New York: Basic Books. . 1988. A Secure Base: Parent-Child Attachment and Healthy Human Development. New York: Basic Books.

Browne, Michael W., and Robert Cudeck. 1993. "Alternative Ways of Assessing Model Fit." In Testing Structural Equation Models, edited by Kenneth A. Bollen, and J. Scott Long, 136-62. Beverly Hills, CA: Sage.

Bynner, John. 2005. "Rethinking the Youth Phase of the Life-Course: The Case for Emerging Adulthood?" Journal of Youth Studies 8, no. 4:367-84.

Chaves, Mark. 2011. American Religion: Contemporary Trends. Princeton, NJ: Princeton University Press.

- 1994. "Secularization as Declining Religious Authority." Social Forces. 72, no. 3:749-74.

Cornwall, Marie, Stan L. Albrecht, Perry H. Cunningham, and Brian L. Pitcher. 1986. "The Dimensions of Religiosity: A Conceptual Model with an Empirical Test." Review of Religious Research 27, no. 3:226-44.

Dein, Simon, and Kenneth I. Pargament. 2012. "On Not Praying for the Return of an Amputated Limb: Conserving a Relationship with God as the Primary Function of Prayer." Bulletin of the Menninger Clinic 76, no. 3:235-59. 
Ellison, Christopher G., and Andrea K. Henderson. 2011. "Religion and Mental Health: Through the Lens of the Stress Process." In Toward a Sociological Theory of Health, edited by Anthony Blasi, 11-44. Leiden: Brill.

Ellison, Christopher G., and Darren E. Sherkat. 1995. "The Semi-Involuntary Institution Revisited: Regional Variations in Church Participation among Black Americans." Social Forces 73:1415-37.

Flory, Richard, and Donald E. Miller. 2008. Finding Faith: The Spiritual Quest of the Post-Boomer Generation. Rutgers, NJ: Rutgers University Press.

Froese, Paul, and Christopher Bader. 2010. America's Four Gods: What we Say about Godand What That Says about Us. New York: Oxford University Press.

Glock, Charles Y., and Rodney Stark. 1968. American Piety. Berkeley: University of California Press.

Granqvist, Pehr. 1998. "Religiousness and Perceived Childhood Attachment: On the Question of Compensation or Correspondence." Journal for the Scientific Study of Religion 37, no. 2:350-67.

. 2003. "Attachment Theory and Religious Conversions: A Review and a Resolution of the Classic Contemporary Paradigm Chasm." Review of Religious Research 45, no. 2:172-87.

Hout, Michael, and Claude S. Fischer. 2002. "Why More Americans Have No Religious Preference: Politics and Generations." American Sociological Review 67:165-90.

Hout, Michael, and Andrew Greeley. 1987. "The Center Doesn't Hold: Church Attendance in the United States, 1940-1984." American Sociological Review 52, no. 3:325-45.

Irby, Courtney A. 2013. "We Didn't Call It Dating': The Disrupted Landscape of Dating Advice for Evangelical Protestant Youth.” Journal of Critical Research on Religion 1, no. 2:177-94.

Johnson, Monica K., Robert Crosnoe, and Glen J. Elder, Jr. 2011. "Insights on Adolescence from a Life Course Perspective." Journal of Research on Adolescence 21, no. 1:273-80.

Krause, Neal. 2004. "Assessing the Relationships among Prayer Expectancies, Race, and Self-Esteem in Late Life.” Journal for the Scientific Study of Religion 43:395-408.

Lee, Matthew, Margaret Poloma, and Stephen G. Post. 2012. The Heart of Religion: Spiritual Empowerment, Benevolence, and the Experience of God's Love. New York: Oxford University Press.

Lenski, Gerhard. 1963. The Religious Factor: A Sociologist's Inquiry. New York: Anchor.

Luhrmann, Tanya. 2012. When God Talks Back: Understanding the American Evangelical Relationship with God. New York: Knopf.

Manglos, Nicolette D. 2010. "Born Again in Balaka: Pentecostal vs. Catholic Narratives of Religious Transformation in Rural Malawi." Sociology of Religion. 71, no. 4:409-31.

McGuire, Meredith B. 2008. Lived Religion: Faith and Practice in Everyday Life. New York: Oxford University Press.

McGuire, Meredith B., and Debra Kantor. 1988. Ritual Healing in Suburban America. New Brunswick, NJ: Rutgers University Press.

Mooney, Margarita A. 2009. Faith Makes Us Live: Surviving and Thriving in the Haitian Diaspora. Berkeley, CA: University of California Press.

Mooney, Margarita A, and Nicolette D. Manglos-Weber. 2014. "Prayer and Liturgy as Constitutive-Ends Practices in Black Immigrant Communities." Journal for the Theory of Social Behaviour 44, no. 4:459-80.

Nelson, James M. 2009. Psychology, Religion, and Spirituality. New York: Springer.

Pearce, Lisa, and Melinda Lundquist Denton. 2011. A Faith of Their Own: Stability and Change in the Religiosity of America's Adolescents. New York: Oxford University Press.

Pearl, Judea. 2012. "The Causal Foundations of Structural Equation Modeling." In Handbook of Structural Equation Modeling, edited by R. Hoyle, 68-91. Newbury Park: Sage. 
Pew Research Center. 2015. "U.S. Religious Landscape Study." http://www.pewforum.org/ religious-landscape-study/, accessed January 31, 2016.

Raftery, Adrian E. 1995. "Bayesian Model Selection in Social Research." Sociological Methodology 25:111-63.

Regnerus, Mark D., Christian Smith, and Brad Smith. 2004. "Social Context in the Development of Adolescent Religiosity." Applied Developmental Science 8, no. 1:27-38.

Rowatt, Wade C., and Lee A. Kirkpatrick. 2002. "Two Dimensions of Attachment to God and Their Relation to Affect, Religiosity, and Personality Constructs." Journal for the Scientific Study of Religion 41, no. 4:637-51.

Schwarz, Gideon. 1978. "Estimating the Dimension of a Model." The Annals of Statistics 6, no. 2:461-4.

Silva, Jennifer M. 2012. "Constructing Adulthood in an Age of Uncertainty." American Sociological Review 77, no. 4:505-22.

Smith, Christian, and Melinda Lundquist Denton. 2005. Soul Searching: The Religious and Spiritual Lives of American Teenagers. New York: Oxford University Press.

Smith, Christian, and Patricia Snell. 2009. Souls in Transition: The Religious and Spiritual Lives of Emerging Adults. New York: Oxford University Press.

Smith, Christian, Kari Christoffersen, Hilary Davidson, and Patricia Snell Herzog. 2011. Lost in Transition: The Dark Side of Emerging Adulthood. New York: Oxford University Press.

Steensland, Brian, Jerry Z. Park, Mark D. Regnerus, Lynn D. Robinson, W. Bradford Wilcox, and Robert D. Woodberry. 2000. "The Measuring of American Religion: Toward Improving the State of the Art." Social Forces 79, no. 1:291-318.

Sullins, D. Paul. 2006. "Gender and Religion: Deconstructing Universality, Constructing Complexity." American Journal of Sociology 112, no. 3:838-80.

Sullivan, Susan Crawford. 2012. Living Faith: Everyday Religion and Mothers in Poverty. Chicago, IL: University of Chicago Press.

Tucker, Ledyard, and Charles Lewis. 1973. "A Reliability Coefficient for Maximum Likelihood Factor Analysis." Psychometrika 38, no. 1:1-10.

Wikstrom, Owe. 1987. "Attribution, Roles and Religion: A Theoretical Analysis of Sunden's Role Theory of Religion and the Attributional Approach to Religious Experience." Journal for the Scientific Study of Religion 26, no. 3:390-400.

Wilcox, Melissa. 2002. "When Sheila's a Lesbian: Religious Individualism among Lesbian, Gay, Bisexual and Transgender Christians." Sociology of Religion 63, no. 4:497-513.

Wilkins, Amy C. 2008. Wannabes, Goths, and Christians: The Boundaries of Sex, Style, and Status. Chicago, IL: University of Chicago Press.

Williams, Rhys H., and Gira Vashi. 2007. "'Hijab' and American Muslim Women: Creating the Space for Autonomous Selves." Sociology of Religion 68, no. 3:269-87.

Wuthnow, Robert. 2007. After the Baby Boomers: How Twenty-and Thirty-Somethings Are Changing the Nature of American Religion. Princeton, NJ: Princeton University Press. 